\title{
ENSINO DE LÍNGUA PORTUGUESA: CONCEPÇÕES E PRÁTICA
}

Maria do Socorro Aguiar de Oliveira Cavalcante Doutoranda no Programa de Pós-Graduação em Letras da Universidade Federal de Alagoas

\section{SITUANDO O PROBLEMA}

Não é de hoje que se fala da crise do sistema educacional brasileiro, e, no seio dela, a crise do ensino de Português, língua materna. Embora amplamente debatido por vários estudiosos ${ }^{1}$, o fenômeno da crise do ensino da lingua continua presente e merecedor de novas reflexões.

Nesse contexto, há que se considerar os avanços dos estudos no âmbito da educação e da lingüistica e os esforços de quantos já produziram um vasto material que explicita novas concepções de ensino, de aprendizagem, e de lingua. Vale destacar, especificamente, as contribuições oferecidas no âmbito da Lingüistica Aplicada quer através de trabalhos publicados que enfocam o processo de ensino/aprendizagem de línguas, quer pela ênfase dada à necessidade de se investir na formação de professores investigadores que vejam sua sala de aula como local de pesquisa, de constante reflexão sobre o que é ensinar/aprender uma lingua (inclusive a materna).

Verificamos, no entanto, que esses estudos, que não são tão recentes, pouco influenciaram na produção de livros didáticos de Lingua Portuguesa, menos ainda, nos cursos de formação de professores de linguas. Diz Suassuna (1995:18):

A questào da crise ou do fracasso no ensino de I.ingua Portuguesa ja for tematizado por lemos (1997. 1983). Pecora (1983). Trasaglia e outros (1984). Franchi (1985). Silva (1984). Cieraldi (1985). (avalcante (1997) entre outros. 
É comum vermos professores insatisfeitos com seu trabalho, frustrados e tomados de uma sensação insuperável de derrota, o que dá lugar a uma certa nostalgia do ensino 'de antigamente'. Espalham-se as queixas: os alunos se caracterizam por um baixo desempenho lingüístico; desprezam a língua; não entendem o que lêem; abusam, na produção textual, de lugares comuns.

Refletindo sobre as causas dessa crise, constatamos vários fatores que a motivaram e a alimentam: a ausência de vontade política de nossos governantes no sentido de resolver ou minimizar o estado de indigência em que se encontra a educação no país; a crescente desvalorização da profissão de professor, que hoje se caracteriza, em todos os níveis, pelo aviltamento salarial, pela fragilidade da formação desse profissional, pela precariedade das condições de trabalho. Tudo isso afeta o trabalho pedagógico de um modo geral, e, de forma específica, o encaminhamento dado à pedagogia da língua, marcado por concepções e práticas equivocadas, ingênua ou propositadamente, mantidas no cotidiano de nossas escolas. E daí o que acontece?

Premidos pela precariedade das condições de trabalho, pela insegurança na condução do fazer pedagógico, os professores, na sua maioria, ou reproduzem antigas práticas já sedimentadas ou se apegam ao livro didático, elegendo-o guia absoluto do trabalho em sala de aula. A solução estaria, então no livro didático? Um bom livro seria capaz de garantir um ensino eficiente e eficaz?

Se assim fosse, a solução para a orientação da prática pedagógica seria muito simples, como diz Verçosa (1985); "mudava-se o livro didático e, conseqüentemente, se conseguiria mudar, pela direção das idéias nele consubstanciadas, o projeto de dominação levado a efeito pela escola." A partir dessa questão, o referido autor desmistifica o discurso de autores ${ }^{2}$ que atribuem ao livro didático "uma capacidade autônoma de garantir uma visão de mundo e sua inculcação, de tal forma que mudando-se o livro consegue-se, automaticamente mudar a prática pedagógica." (op.cit.), 
concluindo que as práticas que se exercem, com os livros e além deles, no cotidiano da escola, têm como referência um modelo prefixado. Ou seja, o que o professor pensa sobre o ensino e sobre a língua influencia sua maneira de ensinar e sua forma de interpretar o livro didático. Daí que, mesmo um bom livro pode ser deturpado, simplificado, assim como um livro medíocre pode ser muito bem utilizado pelo professor, que trabalhando de forma crítica, poderá desconstruí-lo. Assumimos, pois, que é a visão de mundo do professor que determina a orientação de sua prática.

Nesse momento, chama-nos a atenção a iniciativa do MEC que, em vez de atacar as causas da crise do ensino, de que já falamos, se propõe a remediar alguns efeitos, elaborando um GUIA DE LIVROS DIDÁTICOS, cujo objetivo é "auxiliar no aperfeiçoamento do processo ensinoaprendizagem" (PNLD,1997:9), orientando os professores "sobre o quê e como ensinar" (op. cit.) grifo nosso.

Ora, todos sabemos que toda metodologia contém em si mesma uma função política que corresponde aos objetivos que se pretende alcançar, a serviço de quê, de quem, e de qual modelo de sociedade. Logo, o como abordar, o como desenvolver uma ação pedagógica, em qualquer área, vem precedido de para quê e para quem. A resposta a estas questões estabelece as diretrizes que deverão nortear outra questão - o quê. Sob esse aspecto, deve-se considerar que a escolha dos conteúdos a serem desenvolvidos em uma aula ou curso deve ser precedida do conhecimento da realidade dos alunos a que se destina, bem como dos propósitos que se pretende atingir com o ensino.

No caso específico de Língua Portuguesa, a resposta ao para quê envolve a clareza tanto no que se refere a uma proposta metodológica quanto a uma concepção de língua e de ensino. 


\section{O ensino de Língua Portuguesa - concepções e práticas}

\subsection{O que é ensinar e o que é aprender?}

O processo de ensino/aprendizagem independentemente da área de conhecimento, tem a linguagem como mediação, já que tanto o processo de apropriação como o de construção de conceitos se faz com e na linguagem "posta a trabalhar quer por aprendizes quer por 'ensinantes': sem linguagem, a relação pedagógica inexiste." (Geraldi:1997.19). Sem linguagem a mediatização e a apropriação/objetivação de saberes são impossiveis. Daí que, como já dissemos anteriormente, o entendimento do professor não só acerca da língua e da linguagem, mas também sobre o conceito de ensino e de aprendizagem influencia consideravelmente sua maneira de abordar o ensino da língua. O que é ensinar e o que é aprender?

Várias são as concepções de ensino e de aprendizagem produzidas ao longo da história que refletem visões diversificadas de homem e de sociedade. Abordaremos a seguir, de forma sucinta, algumas concepções que, a nosso ver, mais marcaram o nosso ideário pedagógico.

$\mathrm{Na}$ pedagogia tradicional, o homem é concebido como essência universal, a-histórica, que deve ser formado para adaptar-se a uma sociedade dada, homogênea e sem conflitos. Cabe à educação a tarefa de redimir os individuos de sua ignorância, através da ilustração da mente e assim adaptá-los à sociedade. Assim sendo, o ensino é entendido como repasse de conhecimentos e a aprendizagem como assimilação mecânica das informações transmitidas.

Contrapondo-se à pedagogia tradicional, surge a escola nova que concebe o homem como existência (também ahistórica), como um ser ativo a quem cabe autodesenvolver-se, de acordo com suas aptidões e diferenças individuais. Partindo do pressuposto de que ninguém ensina nada a ninguém, essa concepção esvazia a função de ensinar e concebe a aprendizagem como descoberta. 
Importada dos Estados Unidos, propugnando a neutralidade cientifica e defendendo a eficiência e a produtividade do processo educativo, surge, no período compreendido entre 1964/1970, a tendência denominada tecnicista. Essa tendência concebe o homem como um ser cognoscivel, conseqüência das forças existentes em seu ambiente sendo seu comportamento controlado por leis científicas. A sociedade é entendida como um fenômeno objetivo cientificamente controlado. O ensino é concebido como aplicação de princípios científicos, comportamentais e tecnológicos em função de resultados pré-estabelecidos; a aprendizagem como mudança de comportamento.

A partir da segunda metade da década de 70 , surgem entre nós as tendências progressistas ${ }^{3}$ que se fundamentam na teoria marxiana da história e concebem o homem como um ser concreto, social, historicamente determinado; a sociedade como um fenômeno dinâmico, constituído de classes e interesses antagônicos, por isso atravessada por conflitos e passivel da transformação.

Segundo essas tendências, o pleno desenvolvimento do indivíduo se dá mediante um processo de autoconstrução, mediante sua atividade de apropriação/objetivação dos resultados da história, socialmente produzidos. Nesse sentido, o ensino é concebido como mediação no processo de apropriação do cotidiano e apropriação dos conteúdos escolares que permitam a elucidação da realidade, ou seja, que permitam a passagem "de uma experiência confusa, fragmentada, a uma visão organizada e unificada." (Saviani: 1980:120). A aprendizagem é entendida como processo de apropriação/(re)criação do saber historicamente produzido, relacionando-o com as experiências de cada um, indo além das aparências da realidade, buscando compreender os nexos das relações que a explicam e são invisiveis num primeiro momento.

O termo progressista é utilizado por Snyders (1974), para designar as tendèncias que, partindo de uma análise critica das realidades sociais, sustentam implicitamente as finalidades sócio-politicas da educação. 


\subsection{Língua, linguagem e gramática}

Abordados a partir de diferentes perspectivas teóricas, os estudos sobre a linguagem remontam à Antiguidade.

Segundo Câmara (1975), em sociedades primitivas inexistiam estudos lingüísticos. A linguagem era um elemento tão natural da vida social, que não se constituia em objeto de estudo especial. Todavia, à medida que as sociedades se tornaram mais complexas, algumas condições propiciaram a análise da linguagem, a partir, principalmente, da invenção da escrita.

$\mathrm{Na}$ Antiguidade, os estudos sobre a linguagem foram bastante desenvolvidos na Índia e na Grécia. Na Índia, privilegiou-se o estudo do certo e do errado por conta da preocupação com a compreensão correta dos textos religiosos dos Vedas. Na Grécia, os estudos foram marcados por reflexões de ordem filosófica, buscando-se a relação entre a lingua e as coisas que ela exprimia. Debatia-se também sobre a natureza da gramática, das regras que subjazem ao uso da linguagem. As bases da gramática grega estão em Aristóteles que desenvolveu um estudo lógico da linguagem, segmentando o discurso em partes e investigando a estrutura da oração.

Os romanos aplicaram ao Latim as principais conquistas lingüisticas dos gregos, mas "o estudo do certo e do errado - com vistas à imposição do Latim clássico sobre as nações que iam constituindo o Império Romano - continua na Idade Média." (Suassuna: 1995:22). Foram essas características, que remontam à Antiguidade, que influenciaram a formação das gramáticas do Português e produziram concepções de linguagem e de gramática, ainda presentes no cotidiano de nossas salas de aula. Nesse contexto, concebe-se a linguagem como expressão do pensamento e a gramática como um conjunto de formas lingüisticas, reduzida a uma correspondência com a organização do pensamento. Estas concepções adequam-se às concepções de ensino e de aprendizagem presentes na tendência tradicional. 
No início do século $X X$, com a divulgação das idéias de Ferdinand de Saussure, inaugura-se 0 Estruturalismo lingüístico. Influenciado pela Sociologia de Durkheim, Saussure estabeleceu uma distinção entre língua e fala, considerando a lingua um sistema abstrato, homogêneo, social, supraindividual, ao passo que a fala seria a realização concreta e individual da lingua. Desse modo, a língua é entendida como um sistema de signos, que por sua vez, seriam unidades compostas de significante e significado, cuja relação era por ele considerada arbitrária. A partir daí, vários teóricos, seguidores ou não de Saussure, contribuíram para o surgimento de várias correntes estruturalistas.

A partir da década de 50 , tendo à frente o lingüista americano Noam Chomski, surge a gramática gerativotransformacional. Preocupado em aplicar, na descrição de uma língua, os métodos formais da Lógica e da Matemática, Chomski procurou tecer uma gramática formal, de base fundamentalmente sintática. Distinguiu a competência lingüística (conhecimento potencial do sistema da língua) do desempenho. Este sujeito a falhas e imperfeições por se tratar do uso que cada falante faz de competência, entendida como a capacidade inata que o falante-ouvinte tem de construir um número infinito de enunciados com base em um conjunto finito de unidades lingüisticas. Nessa teoria, lingua é entendida como um sistema estável, imutável de formas lingüisticas, não é tratada em sua variedade de usos e funções e sua gramática é considerada como um conjunto de regras cuja aplicação produz enunciados gramaticais. Tanto o estruturalismo lingüístico como o gerativismo orientam a prática de ensino de linguas na tendência tecnicista.

A divulgação das idéias da gramática gerativotransformacional provocou polêmicas acerca do seu modelo, particularmente no tocante aos limites entre a sintaxe e a semântica. Pêcheux (1969), Roulet (1978), Verón (1980), entre outros, apontam limitações às referidas abordagens lingüísticas. As preocupaçōes dos estudiosos começam a se dirigir para a superação do nivel da frase e para a inclusão, na análise da linguagem, de novos fatores como texto, contexto, intenções e atitudes do falante em relação à prática da língua. Caminha-se 
para um redimensionamento da lingüística como ciência, cujo objeto é o discurso.

Nesse novo momento, situamos a Pragmática e a Análise do Discurso. Na perspectiva pragmática, a linguagem é considerada como forma de ação. "Cada ato de fala (batizar, permitir, mas também prometer, interrogar, afirmar, etc.) é inseparável de uma instituição, aquela que este ato pressupõe pelo simples fato de ser realizado." (Maingueneau: 1989:29).

Quanto à Análise do Discurso, bifurca-se em duas tendências. Uma, considerada extensão da Lingüistica vertente anglo-americana - preocupa-se apenas com as formas de organização dos elementos que constituem o texto sem a preocupação com as formas de instituição do sentido; outra - a vertente européia - "parte de uma relação necessária entre o dizer e as condições de produção desse dizer" (Orlandi: 1986) e coloca a exterioridade como marca fundamental.

Essa vertente entende a linguagem como mediação entre o homem e sua realidade, como lugar de conflito, de confronto ideológico; a língua como materialidade constituída de regras e categorias e, ao mesmo tempo, como diz Maingueneau (1995), "lugar de investimentos psiquicos e sociais" do sujeito nas suas relações com os homens e com a natureza; ou ainda, como diz Voese (1996): "sistematização aberta, constituida e constituinte, resultado e possibilidade que reflete enquanto realidade em movimento inacabado que ocorre na complexidade social." Assim sendo, não pode ser estudada fora do contexto sócio-histórico. Nessa perspectiva, a gramática é entendida como reflexão sobre a regularidade e imprevisibilidade dos fenômenos lingüisticos, ou seja, a legalidade da língua. Isso significa dizer que falar uma língua é ser capaz de usar as regras dessa língua na produção de textos inteligiveis.

Ora, como já dissemos no início deste capítulo, o processo de apropriação/construção do conhecimento, se faz com e na linguagem. A linguagem, diz Suassuna (1995:118):

é também uma forma de conhecimento.[...] Deve ser entendida na sua relação dialética com o saber: ela é saber, é 
produzida pelo/com o saber, produz saber e me faz entender e recriar o saber, e assim por diante numa cadeia ininterrupta.

É com e através dela que compreendemos o mundo, expressamos nossa compreensão e buscamos os modos de intervir sobre ele, transformando-o. Nessa perspectiva, a gramática é entendida como reflexão sobre a regularidade e imprevisibilidade dos fenômenos lingüísticos

Isso implica uma clareza não só quanto à metodologia, mas, principalmente, quanto às concepções de lingua e de gramática, quanto aos objetivos de ensino da língua, uma vez que, como já foi explicitado, toda metodologia contém em si uma função política que corresponde aos objetivos que se pretende alcançar, a serviço de quê, de quem e de qual modelo de sociedade.

A nosso ver, é bastante sintomática a posição do MEC, quando em seu discurso apregoa a importância da elaboração de um "Guia" para auxiliar "no aperfeiçoamento do processo de ensino/aprendizagem". Na ausência de políticas eficazes que viriam minimizar a situação caótica em que se encontra o ensino, em todos os níveis, O MEC acena com receituários que, se aplicados de forma eficiente, poderão reduzir alguns efeitos da crise, mas as causas permanecerão e continuarão alimentando o atual quadro de indigência do nosso sistema de ensino.

Foi feita uma avaliação de livros didáticos, orientada por princípios que deveriam ser levados em consideração pelos técnicos de cada área, tais como: (PNLD,1997:10)

Que concepções de Linguagem, Matemática, História [...] os livros manifestam?

Quais os conteúdos privilegiados?

Com que rigor e acerto tais conteúdos são tratados?

Que metodologia é empregada ou preconizada?

Como todos esses aspectos se articulam numa proposta global?

Há coerência entre a proposta didático-pedagógica e o projeto gráfico?

O livro do professor orienta o processo de ensino? 
Feitas as análises, os livros foram classificados em três categorias (por estrelas):

$\star \star \star$ recomendados com distinção: são os livros que se destacam entre os de boa qualidade por se aproximarem mais que os outros do ideal representado pelos princípios e critérios referidos;

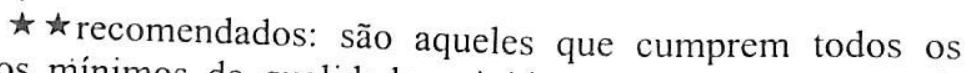
requisitos mínimos de qualidade exigidos por este momento de processo de avaliação, ainda que possam ser objeto de uma ou outra restrição;

‡ recomendados com ressalvas: nesta categoria estão reunidos os trabalhos meritórios que, por este ou aquele motivo, não estão a salvo de alguma restrição pertinente. (PNLD, 1997:12).

\subsection{A prática pedagógica}

Aonde queremos chegar? Nesse breve estudo, que é apenas uma introdução ao que pretendemos desenvolver num futuro próximo, tomaremos apenas duas questões: 1.que concepção de língua e de gramática os livros classificados na categoria três estrelas veiculam? 2. até que ponto esses livros influenciam a prática cotidiana do professor "orientando o quê e como ensinar" ?

Dos livros de Língua Portuguesa, apenas uma editora foi contemplada com a classificação três estrelas - a FTD. A coleção intitula-se ALP - Análise, Linguagem e Pensamento. Dessa coleção, tomamos o livro de quinta série. Vejamos o que diz o GUIA de livros didáticos - (PNLD 1999:35):

Este volume faz parte de uma coleção que, declarando uma concepção sócio-construtivista e assumindo a perspectiva das práticas de letramento - além de uma vinculação com áreas de estudo como a Análise do Discurso e a Sociolingüística - pretende promover atividades de linguagem, enfatizando seu uso e sua funcionalidade, em processos de interação. Dessa ótica, o aluno é o sujeito de sua própria aprendizagem, responsável pela construção de seu conhecimento. 
Em seguida, foi feita uma análise com relação às diferentes atividades abordadas no livro.

\section{Quanto à leitura:}

É a linha mestra da obra, que estabelece a possibilidade de exploração positiva da diversidade como marca de autenticidade.[...] Nesta perspectiva são apresentados textos práticos, $[\ldots]$ informativos,[...] literários e ainda extraverbais (pintura, escultura etc.) o que favorece também o trabalho com a intertextualidade. (op.cit.).

2. Quanto às atividades de produção de texto:

têm como marca, advinda da proposta de leitura, a diversidade.[...] O aluno é levado a produzir uma quantidade significativa de textos de diferentes tipos e gêneros e mesmo de diferentes registros. [...] Avaliação da produção é outro ponto alto, pois tematiza tanto aspectos característicos da cada produção, como evidencia preocupação com a correção gramatical, a clareza da linguagem e o uso correto da pontuação.(op.cit.36).

3.Quanto ao estudo dos aspectos gramaticais:

Assumindo trabalhar a nomenclatura oficial, que deve "ser explicada, através de exemplos, para que os alunos possam localizar, refletir, pensar e atuar sobre os aspectos gramaticais do texto", a proposta oscila entre justificativas sobre a utilidade dos conhecimentos gramaticais até $[\ldots]$ os estudos mais recentes que acreditam que "o aluno só constrói os conceitos gramaticais e os aplica quando compreende o seu uso". [...] Em resumo, esta obra, excelente exemplo de integração entre teoria e prática pedagógica, prioriza a aprendizagem como um processo no centro do qual está o aluno e sua interação com o mundo. [...] Por tudo isso, este livro pode ser considerado um valiosos auxiliar, para o trabalho em sala de aula. (PNLD 1999:36).

Não é pretensão nossa, neste trabalho, fazer uma análise aprofundada do livro em questão. No entanto, tomando apenas as afirmações do "GUIA" (1999:36), entendemos que as concepções de ensino-aprendizagem que o embasam são respectivamente as de mediação/construção do conhecimento, em que o aluno é o sujeito do processo: "esta obra, excelente exemplo de integração teoria e prática pedagógica, prioriza a 
aprendizagem como um processo no centro do qual está o aluno e sua interação com o mundo".

Também podemos, a partir dos comentários do "GUIA", inferir as concepções de lingua e de gramática. À afirmação: "Declarando uma concepção sócio-construtivista [...] pretende promover atividades de linguagem, enfatizando seu uso e sua funcionalidade, em processos de interação.", subjaz uma concepção pragmática da língua que a entende como instrumento de interação. Quanto à gramática, assim se posiciona o já referido "GUIA":

Assumindo trabalhar a nomenclatura oficial, que deve "ser explicada, através de exemplos para que os alunos possam localizar, refletir, pensar e atuar sobre os aspectos gramaticais" a proposta oscila entre a justificativa sobre a utilidade dos conhecimentos gramaticais [...] até os estudos [...] que acreditam que o aluno só constrói os conceitos gramaticais e os aplica quando entende o seu uso.

Se entendemos corretamente esta afirmação, podemos daí inferir uma concepção de gramática como reflexão sobre a regularidade e a imprevisibilidade dos fenômenos gramaticais enquanto constitutivos da língua.

Como já dissemos anteriormente, não podemos constatar se, realmente, essas concepções estão presentes nas atividades do livro didático em questão, uma vez que não fizemos uma análise aprofundada do mesmo. Baseamo-nos apenas na avaliação feita pela equipe técnica do MEC.

Passaremos agora à segunda questão: até que ponto os livros didáticos influenciam a prática pedagógica dos professores? Ao utilizar os livros três estrelas, escolhidos segundo os critérios do MEC, terão os referidos professores conseguido superar sua concepção e sua prática tradicionais?

Foi com o intuito de encontrar resposta para estas questões que acompanhamos um professor de Lingua Portuguesa, usuário do livro didático em questão. O que constatamos?

1. A primeira providência do professor foi separar as atividades de Leitura e Produção de Texto das de Gramática. 
2. Nessa separação, ao contrário do que diz o "GUIA" (1999:36), "a proposta de leitura é a linha mestra da obra", a professora privilegia o trabalho com a gramática, uma vez que, na separação das atividades, apenas um dia fica reservado às atividades de "PTL" - produção textual e leitura (denominação dada pela professora) enquanto são destinados dois dias para as atividades de estudos gramaticais.

3. O livro didático só é utilizado nas aulas de "PTL". Para as atividades de estudos lingüisticos, o professor adotou uma gramática ${ }^{4}$ de onde retira conceitos (que 0 aluno deve memorizar) e exercícios (que o aluno deve resolver).

Por ai já podemos perceber que o professor, mesmo utilizando o livro didático, não segue as orientações contidas no mesmo ou as segue parcialmente, uma vez que o livro só é utilizado nas atividades de leitura e produção de texto. Nas aulas de gramática, a professora segue integralmente as orientações contidas na Gramática Essencial llustrada de Sacconi (1994). adotada:

Vejamos um exemplo, retirado da referida gramática

\section{Substantivo}

Tudo o que existe no mundo - ou que imaginamos existir - tem um nome: casa, escola, livro, Deus, Brasil, amor, felicidade, fada, etc.

Esse nome é justamente o substantivo.

Tipos de substantivo

O substantivo pode ser comum ou próprio, simples ou composto, primitivo ou derivado, concreto ou abstrato.

(A seguir temos as definições, seguidas de exemplos de cada um dos tipos de substantivos referidos)

Coletivos

Todo substantivo comum que indica, mesmo no singular, vários seres da mesma espécie, é um coletivo.

Gramática Essencial Ilustrada, de Luiz Antonio Sacconi. 
Ex: exército (muitos soldados), manada (muitos elefantes, ou muitos cavalos, ou muitos búfalos, etc) Eis alguns exemplos de coletivos $[\ldots]$.

\section{Exercicios}

\section{Encontre os substantivos:}

a) Uma enorme baleia foi encontrada ontem na reserva biológica do Rio- de Janeiro.[...]

b) A inveja, antes de ser pecado é infelicidade.

c) Deus não é algo que se prove é um ser que se sente.[...]

2. Encontre os substantivos compostos: vaga-lume, semivogal, pontapé, puxa-saco, pão-duro[...]

3. Encontre os substantivos derivados: lamaçal, barrento, olho, cabeludo, tufão[...]

4. Diga quais são os concretos e quais são os abstratos: saci, nuvem, Deus, pulmão, oxigênio[...]

5. Vi um bando de cafajestes . Repita essa frase, mudando os coletivos, segundo esses nomes: bois, artistas, inimigos, sonhos[...]

6. Complete as frases com coletivos adequados:

a) uma porção de mapas forma um?

b) uma porção de peixes juntos forma um?

c) uma porção de discos forma uma ?

Como podemos observar, as atividades descritas nessa amostragem reduzem-se a exercícios de identificação, reprodução e complementação de frases, sem nenhuma relação com a compreensão e produção de textos, sem nenhuma relação com o uso da língua, conseqüentemente, sem nenhuma significação para o aluno. Ao contrário do que diz o "GUIA" com relação às atividades do livro didático - "o aluno só constrói os conceitos gramaticais e os aplica quando compreende o seu uso" -, nas atividades desenvolvidas pelo professor, os alunos apenas memorizam conceitos gramaticais e realizam exercicios de fixação cujas respostas exigem a automatização prévia da metalinguagem. 
Nessas atividades, percebe-se claramente que o ensino é concebido como repasse de conhecimentos (de alguém que sabe para alguém que não sabe); que a aprendizagem é vista como reprodução, assimilação mecânica de conceitos e normas; a língua como uma abstração, um sistema de regras estável e homogêneo e a gramática como um conjunto de normas que devem ser seguidas por quem quer falar $e$ escrever "corretamente" a variedade padrão.

Com essas atividades, é impossivel pretender que o aluno desenvolva suas possibilidades de, como falante, expressar sua linguagem, operando com e sobre ela. Constatamos, com isso, que a prática do professor distanciase, e muito, do que, segundo a avaliação do MEC, teria a "leitura como linha mestra" (PNLD 1999:36); daria ênfase nas situações de uso da linguagem e priorizaria "a aprendizagem como um processo no centro do qual está o aluno e sua interação com o mundo e com os outros".

\section{CONCLUSÃO}

Diante do exposto, podemos afirmar que é um grande equivoco pensar que apenas a substituição de um livro didático mudaria a prática pedagógica. No caso específico do Português, língua materna, a superação da crise e do fracasso do ensino da língua, passa, principalmente, pela busca de concepções de ensino e de lingua diferentes das que acabamos de descrever, pois uma mudança de concepção de língua/linguagem constrói não só uma nova metodologia mas um novo conteúdo de ensino.

Para que isso aconteça, é preciso, sobretudo, lutar pela melhoria dos cursos de formação de professores; é preciso assegurar aos professores um embasamento sólido, quer no âmbito da formação geral, quer no âmbito da formação lingüística, para que ele seja capaz de transformar sua sala de aula em um espaço de construção do conhecimento, em que o aluno/sujeito apreenda a realidade, expresse o que sobre ela compreendeu e possa, a partir daí, buscar mecanismos para transformá-la. 
Nesse sentido, é preciso formar o professor para que seja, ele próprio investigador de sua prática, pois, como diz Cavalcanti (1991:142):

A prática da sala de aula como tema permanente de investigação por parte do professor deverá certamente resultar em uma reflexão questionadora que muito contribuirá para o desenvolvimento e fortalecimento da área de ensino de línguas no Brasil tanto em termos da formulação de teorias como em termos da prática de ensino de línguas materna e estrangeira.

\section{REFERÊNCIAS BIBLIOGRÁFICAS}

CAVALCANTE, Maria do Socorro Aguiar de Oliveira. Produção de texto na escola: Homogeneização do não homogêneo. Maceió, 1997. Dissertação de Mestrado. Universidade Federal de Alagoas,

CAVALCANTI, Marilda; MOITA LOPES, Luiz Paulo. Implementação de pesquisa na sala de aula de línguas no contexto brasileiro. Trabalhos de Lingüistica Aplicada. Campinas, 1991.

CÓCCO, Maria Fernandes; HAILER, Marco Antônio. ALP Análise, Linguagem e Pensamento: a diversidade de textos numa proposta socioconstrutivista. São Paulo: FTD, 1994.

FRANCHI, Carlos. Criatividade e gramática. Trabalhos em Lingüística Aplicada. Campinas, n. 9, 1997.

MAINGUENEAU, Dominique. Novas tendências em análise do discurso. Campinas: Pontes, 1989.

MAINGUENEAU, Dominique. L'analyse des discours constituants. Langages - Les Analyses du discours en France. 117. Paris: Larousse, 1995.

ORLANDI, Eni P. A Análise do Discurso: algumas observações. São Paulo, D.E.L.T.A., n. 1, 1986. 
PNLD,1999 - GUIA de livros didáticos, $5^{a}$. a $8^{a}$. séries. Brasília, MEC, 1998.

POSSENTI, Sírio. Gramática e política. IEL, UNICAMP (texto mimeo)

SACCONI, Luiz Antônio. Gramática Essencial e Ilustrada. São Paulo: Atual,1994.

SuASSUNA, Livia. Ensino de Lingua Portuguesa numa perspectiva pragmática. São Paulo: Papyrus, 1995.

VERÇOSA, Élcio de Gusmão. Ideologia e prática pedagọgica escolar. Recife, 1985. Dissertação de Mestrado, Universidade Federal de Pernambuco.

VOESE, Ingo. Interação e ensino. Leitura. Maceió, EDUFAL, n. 9/10, 1993. 